\title{
Administration of recombinant activated factor VII in the intensive care unit after complex cardiovascular surgery: Clinical and economic outcomes
}

\author{
Walter E. Uber, PharmD, ${ }^{\mathrm{a}}$ John M. Toole, MD, ${ }^{\mathrm{b}}$ Martha R. Stroud, MS, ${ }^{\mathrm{b}}$ Jason S. Haney, PharmD, ${ }^{\mathrm{a}}$ \\ John Lazarchick, MD, ${ }^{\mathrm{c}}$ Fred A. Crawford, Jr, MD, ${ }^{\mathrm{b}}$ and John S. Ikonomidis, MD, $\mathrm{PhD}^{\mathrm{b}}$
}

\begin{abstract}
Objective: Refractory bleeding after complex cardiovascular surgery often leads to increased length of stay, cost, morbidity, and mortality. Recombinant activated factor VII administered in the intensive care unit can reduce bleeding, transfusion, and surgical re-exploration. We retrospectively compared factor VII administration in the intensive care unit with reoperation for refractory bleeding after complex cardiovascular surgery.
\end{abstract}

\begin{abstract}
Methods: From 1501 patients who underwent cardiovascular procedures between December 2003 and September 2007, 415 high-risk patients were identified. From this cohort, 24 patients were divided into 2 groups based on whether they either received factor VII in the intensive care unit $(\mathrm{n}=12)$ or underwent reoperation $(\mathrm{n}=12)$ for refractory bleeding. Preoperative and postoperative data were collected to compare efficacy, safety, and economic outcomes.
\end{abstract}

\begin{abstract}
Results: In-hospital survival for both groups was $100 \%$. Factor VII was comparable with reoperation in achieving hemostasis, with both groups demonstrating decreases in chest tube output and need for blood products. Freedom from reoperation was achieved in $75 \%$ of patients receiving factor VII, whereas reoperation was effective in achieving hemostasis alone in $83.3 \%$ of patients. Prothrombin time, international normalized ratio, and median operating room time were significantly less $(P<.05)$ in patients who received factor VII. Both groups had no statistically significant differences in other efficacy, safety, or economic outcomes.
\end{abstract}

Conclusions: Factor VII administration in the intensive care unit appears comparable with reoperation for refractory bleeding after complex cardiovascular surgical procedures and might represent an alternative to reoperation in selected patients. Future prospective, randomized controlled trials might further define its role. (J Thorac Cardiovasc Surg 2011;141:1469-77)

\section{Supplemental material is available online.}

Refractory bleeding is a potentially serious complication of complex cardiovascular surgery. ${ }^{1-7}$ Topical hemostatic agents, transfusion of red cells and clotting factors, and re-exploration are used when appropriate. ${ }^{1-7}$ Bleeding, massive transfusion, and re-exploration increase hospital length of stay (LOS), overall cost, morbidity, and mortality. 1,7 When standard hemostatic interventions fail, alternative means of reversing coagulopathy are required.

\footnotetext{
From the Departments of Pharmacy Services, ${ }^{\text {a }}$ Cardiothoracic Surgery, ${ }^{\mathrm{b}}$ and Pathology and Laboratory Medicine, ${ }^{\mathrm{c}}$ Medical University of South Carolina, Charleston, SC.

Disclosures: Authors have nothing to disclose with regard to commercial support. Read at the 90th Annual Meeting of The American Association for Thoracic Surgery, Toronto, Ontario, Canada, May 1-5, 2010.

Received for publication April 30, 2010; revisions received Nov 12, 2010; accepted for publication Feb 25, 2011; available ahead of print April 1, 2011.

Address for reprints: John S. Ikonomidis, MD, PhD, Division of Cardiothoracic Surgery, Medical University of South Carolina, Suite 7030, 25 Courtney Dr, Charleston, SC 29425-2950 (E-mail: ikonomij@musc.edu).

$0022-5223 / \$ 36.00$

Copyright (c) 2011 by The American Association for Thoracic Surgery doi:10.1016/j.jtcvs.2011.02.033
}

Recombinant activated factor VII (rFVIIa; NovoSeven; Novo Nordisk, Princeton, NJ) is approved by the US Food and Drug Administration for the treatment of bleeding in patients with hemophilia A or B with inhibitors to factor VIII or IX, respectively, for surgical procedures in this patient population and in patients with congenital factor VII deficiency and Glanzmann's thromboasthenia. ${ }^{8}$ Off-label use of rFVIIa has expanded to other postsurgical populations, including cardiovascular surgery for the control of hemorrhage. ${ }^{9-19}$ In addition, rFVIIa administration in the intensive care unit (ICU) after cardiovascular procedures reduces bleeding and transfusion requirements and might avoid re-exploration. 9,10,12,14-16,18,19 However, concerns over the safety and cost of rFVIIa have created controversy about its use in this patient population. .,19,20 $^{2}$

The purpose of this study is to evaluate the clinical and economic outcomes of initial rFVIIa administration in the ICU after complex cardiovascular surgery compared with reoperation to treat refractory postoperative bleeding.

\section{MATERIALS AND METHODS \\ Patient Population}

A retrospective chart review was conducted of all adult cardiovascular surgery patients 18 years of age or older at the Medical University of South 


$$
\begin{aligned}
& \text { Abbreviations and Acronyms } \\
& \begin{aligned}
\text { ICU } & =\text { intensive care unit } \\
\text { LOS } & =\text { length of stay } \\
\text { MUSC } & =\text { Medical University of South Carolina } \\
\text { OR } & =\text { operating room } \\
\text { PRBC } & =\text { packed red blood cell } \\
\text { rFVIIa } & =\text { recombinant activated factor VII } \\
\text { TF } & =\text { tissue factor }
\end{aligned}
\end{aligned}
$$

Carolina (MUSC) between December 2003 and September 2007. A highrisk subset was defined as patients undergoing cardiac transplantation, aortic surgery, redo operations, or combined multiple cardiac procedures. Patients requiring thoracoabdominal aortic procedures, use of a ventricular assist device or extracorporeal membrane oxygenation, surgical correction for congenital heart disease, cardiovascular procedures in the setting of multiple trauma, resection of cardiac tumors, and pericardiectomy and patients who died in the operating room (OR) were excluded. Patients who received $\mathrm{rFVII}$ in the OR during the primary procedure were also excluded. From this high-risk subset, patients were further excluded if they received antifibrinolytics other than aprotinin or anticoagulants other than heparin. This study was approved by our institutional review board, and individual patient consent was waived.

The remaining patients in this high-risk subset were screened for postoperative bleeding, which was defined as a chest tube output of $3 \mathrm{~mL}$. $\mathrm{kg}^{-1} \cdot \mathrm{h}^{-1}$ or greater for 2 or more consecutive hours and/or requirement for re-exploration for bleeding, cardiac tamponade, or hemothorax within the first 24 hours after the primary operation. Patients meeting the above criteria for bleeding were then evaluated for use of rFVIIa in the ICU or reoperation. All patients who received rFVIIa in the ICU or underwent reoperation for bleeding within the first 24 hours were enclosed in this cohort. Patients' demographics, preoperative risk factors, rFVIIa dosing characteristics, blood product use, coagulation laboratory values, operative characteristics, the need for reoperation for bleeding after the primary procedure, chest tube output, in-hospital outcomes, and hospital economic data were recorded. Available data were collected through the Division of Cardiothoracic Surgery's Society of Thoracic Surgeons Adult Cardiac Surgery database. The European System for Cardiac Operative Risk Evaluation (EuroSCORE) score system was used to evaluate the severity risk for each group.

\section{Threshold for Reoperation or rFVIIa Use}

Before 2006, rFVIIa was not used in the ICU after cardiovascular surgery at MUSC. Reoperation was the primary modality in treating refractory postoperative bleeding. The decision for reoperation was made by the surgical team after considering the following criteria: (1) chest tube output of $3 \mathrm{~mL} \cdot \mathrm{kg}^{-1} \cdot \mathrm{h}^{-1}$ or greater for 2 or more consecutive hours; (2) reversal of coagulopathy, as evidenced by normalization of coagulation laboratory values (international normalized ratio, $\leq 1.5$; platelet count, $\geq 100,000$ / $\mathrm{mm}^{3}$; and fibrinogen level, $>200 \mathrm{mg} / \mathrm{dL}$ ); (3) correction of the patient's core body temperature to $35^{\circ} \mathrm{C}$ or greater; and (4) adequate heparin reversal with protamine defined as an activated partial thromboplastin time of 1.5 times or less than our laboratory control (45 seconds). Patients were also considered candidates for reoperation if there was concern for surgical sources of bleeding, evidence of cardiac tamponade, mediastinal hematoma, or large hemothorax.

In 2006, we began using rFVIIa as an alternative to reoperation in postoperative patients with refractory bleeding after cardiovascular surgery. The decision to administer rFVIIa was made by the surgical team after considering the same criteria as above, provided there was a low index of suspicion for a surgical cause of bleeding and no evidence of cardiac tamponade, mediastinal hematoma, or hemothorax.

\section{End Points}

The primary end points of this study were efficacy, adverse events, and cost. Efficacy was determined by means of (1) evaluation of chest tube output and avoidance of reoperation, (2) blood product use before and after intervention, and (3) outcome measures, including OR time, ventilator time, ICU and hospital LOS, and survival. Adverse events were compared between the groups with regard to complications including pneumonia, mediastinitis, thrombosis and thromboembolism, renal failure defined as an increase in serum creatinine level to greater than $2 \mathrm{mg} / \mathrm{dL}$ or 2 times the most recent preoperative level or a new requirement for dialysis, and death. Cost was compared by using hospital cost, charges, reimbursement, and profit. To account for time-related inflationary changes, cost information was normalized to 2009 by using the US Bureau of Labor Statistics Consumer Price Index. Additionally, hospital costs were also adjusted for increases in hospital capital expenditures over time.

\section{Statistical Analysis}

Continuous variables are reported as medians with ranges caused by data nonparametricity. Categorical variables are reported as counts with percentages. Preintervention and postintervention chest tube outputs were examined with the Wilcoxon matched-pairs signed-rank test. Demographics, risk factors, operative characteristics, outcome parameters, and financial data were compared between the rFVIIa and reoperation groups by using the Fisher exact test for categorical variables and the MannWhitney test for continuous variables.

\section{RESULTS}

\section{Demographic and Procedural Data}

Between December 2003 and September 2007, 1501 patients underwent cardiovascular procedures at MUSC. After exclusions, 421 cases performed in 415 high-risk patients were identified and subsequently screened for postoperative bleeding. In this cohort 25 patients were found to meet the postoperative bleeding criteria. This resulted in a calculated incidence of excessive postoperative bleeding of 5.9\% (25/ 421). Twelve patients received rFVIIa in the ICU after their primary operation as the primary mode of therapy for refractory coagulopathy, and 12 patients underwent reoperation for bleeding without receiving rFVIIa in the ICU. One patient underwent neither intervention and was included to determine the incidence of postoperative bleeding.

There were no statistically significant differences in patients' demographics, history of thromboembolism, coagulopathy, previous cardiac surgery, anticoagulant use, or preoperative risk factors for bleeding between the groups. The additive EuroSCORE was not significantly different between groups and demonstrated a high-risk severity at baseline (Table 1).

Types of operations were similar between groups. Circulatory arrest time was significantly longer in the reoperation group (18 vs 10 minutes, $P=.01$ ), but otherwise, there were no differences in operative characteristics. Intraoperative use of additional pharmacologic agents was infrequent and similar between groups. Additional pharmacologic agents to control bleeding in the ICU were used in 8 patients 
TABLE 1. Comparison of patients' demographics and risk factors for bleeding and thrombosis in patients receiving rFVIIa or reoperation for refractory coagulopathy in the intensive care unit

\begin{tabular}{|c|c|c|c|}
\hline Demographics/risk factor & $\begin{array}{c}\text { rFVIIa } \\
(n=12) \\
\end{array}$ & $\begin{array}{l}\text { Reoperation } \\
(\mathrm{n}=12) \\
\end{array}$ & $\begin{array}{c}P \\
\text { value } \\
\end{array}$ \\
\hline \multicolumn{4}{|l|}{ Age (y) } \\
\hline Median & 64 & 61 & .671 \\
\hline Range & $24-78$ & $18-81$ & \\
\hline \multicolumn{4}{|l|}{ EuroSCORE (additive) } \\
\hline Median & 7.5 & 9.0 & .178 \\
\hline Range & $3-13$ & $5-19$ & \\
\hline Sex (female) & $1(8 \%)$ & $4(33 \%)$ & .317 \\
\hline \multicolumn{4}{|l|}{ Race } \\
\hline White & $11(92 \%)$ & $10(83 \%)$ & 1.000 \\
\hline African American & $1(8 \%)$ & $2(17 \%)$ & \\
\hline History of coagulopathy & 0 & 0 & \\
\hline Renal insufficiency & $1(8 \%)$ & $3(25 \%)$ & .590 \\
\hline Peripheral vascular disease & $1(8 \%)$ & $0(0 \%)$ & 1.000 \\
\hline Previous MI & $0(0 \%)$ & $2(17 \%)$ & .478 \\
\hline Previous CVA & $1(8 \%)$ & $0(0 \%)$ & 1.000 \\
\hline Emergency status & $2(17 \%)$ & $2(17 \%)$ & 1.000 \\
\hline Redo operations & $3(25 \%)$ & $3(25 \%)$ & 1.000 \\
\hline Preoperative anticoagulants & $7(58 \%)$ & $6(50 \%)$ & 1.000 \\
\hline Aspirin & $4(33 \%)$ & $6(50 \%)$ & .680 \\
\hline Coumadin & $1(8 \%)$ & $0(0 \%)$ & 1.000 \\
\hline Heparin/LMWH & $0(0 \%)$ & $2(27 \%)$ & .478 \\
\hline Clopidogrel & $1(8 \%)$ & $0(0 \%)$ & 1.000 \\
\hline Other & $3(25 \%)$ & $0(0 \%)$ & .217 \\
\hline Multiple agents & $2(17 \%)$ & $2(17 \%)$ & 1.000 \\
\hline \multicolumn{4}{|l|}{ Insurance status } \\
\hline Government & $8(67 \%)$ & $6(50 \%)$ & .426 \\
\hline Private & $3(25 \%)$ & $5(42 \%)$ & \\
\hline Other & $0(0 \%)$ & $1(8 \%)$ & \\
\hline Uninsured & $1(8 \%)$ & $0(0 \%)$ & \\
\hline
\end{tabular}

rFVIIa, Recombinant activated factor VII; $M I$, myocardial infarction; $C V A$, cerebrovascular accident; $L M W H$, low-molecular-weight heparin.

receiving $\mathrm{rFVIIa}$ and 5 patients undergoing reoperation $(P=.41)$. The most common agent used was protamine in the OR and ICU (Table 2).

\section{Threshold for Reoperation or rFVIIa Use}

Transfusion requirements with packed red blood cells (PRBCs), fresh frozen plasma, platelets, and cryoprecipitate intraoperatively and in the ICU before intervention are shown in Figure 1, $A$ and $B$. Eleven of 12 patients in the rFVIIa group met chest tube output criteria. One patient initially drained in excess of $3 \mathrm{~mL} \cdot \mathrm{kg}^{-1} \cdot \mathrm{h}^{-1}$, subsequently stopped, and then trended back up to $2.2 \mathrm{~mL} \cdot \mathrm{kg}^{-1} \cdot \mathrm{h}^{-1}$. This patient received rFVIIa and was included in our analysis. Seven of 12 patients in the reoperation group met chest tube output criteria. Of those who did not, 3 were suspected of having surgical bleeding at the discretion of the attending surgeon, and 2 had evidence of hemothorax requiring evacuation and therefore were included in our analysis. No differences were observed in coagulation values, body temperature, $\mathrm{pH}$, ionized calcium concentrations, or chest
TABLE 2. Primary operative characteristics in patients who received rFVIIa or reoperation for refractory coagulopathy in the intensive care unit

\begin{tabular}{|c|c|c|c|}
\hline Characteristics & $\begin{array}{c}\text { rFVIIa } \\
(n=12)\end{array}$ & $\begin{array}{l}\text { Reoperation } \\
(\mathbf{n}=12)\end{array}$ & $\begin{array}{c}P \\
\text { value }\end{array}$ \\
\hline \multicolumn{4}{|l|}{ Type of operation, $\mathrm{n}(\%)$} \\
\hline Aorta surgery & $6(50 \%)$ & $7(58 \%)$ & \multirow[t]{4}{*}{.815} \\
\hline Multiple procedures & $3(25 \%)$ & $2(17 \%)$ & \\
\hline Cardiac transplantation & $2(17 \%)$ & $1(8 \%)$ & \\
\hline Redo & $1(8 \%)$ & $2(17 \%)$ & \\
\hline \multicolumn{4}{|l|}{ CPB (min) } \\
\hline Median & 189 & 168 & \multirow[t]{2}{*}{.551} \\
\hline Range & $109-275$ & $105-248$ & \\
\hline \multicolumn{4}{|l|}{ Crossclamp (min) } \\
\hline Median & 108 & 109 & \multirow[t]{2}{*}{.928} \\
\hline Range & 74-191 & 69-162 & \\
\hline \multicolumn{4}{|l|}{ Circulatory arrest (min) } \\
\hline Median & 10 & 18 & \multirow[t]{2}{*}{.010} \\
\hline Range & $6-16$ & $14-24$ & \\
\hline \multicolumn{4}{|c|}{$\begin{array}{l}\text { Additional agents given to } \\
\text { control bleeding, } \mathrm{n}(\%)\end{array}$} \\
\hline OR, primary operation & $2(17 \%)$ & $3(25 \%)$ & 1.000 \\
\hline Intensive care unit & $8(67 \%)$ & $5(42 \%)$ & .414 \\
\hline Protamine & $8(67 \%)$ & $4(33 \%)$ & .220 \\
\hline DDAVP & $0(0 \%)$ & $3(25 \%)$ & .217 \\
\hline Vitamin K & $0(0 \%)$ & $1(8 \%)$ & 1.000 \\
\hline Multiple agents & $0(0 \%)$ & $2(17 \%)$ & .478 \\
\hline
\end{tabular}

tube output before intervention (see Table E1). No differences were observed in intraoperative or preintervention ICU blood use between groups. The average dose of rFVIIa was $89.9 \pm 7.1 \mu \mathrm{g} / \mathrm{kg}$ per dose. No patient received more than 1 dose.

\section{End Points for Efficacy}

The rFVIIa group had a significant decrease in prothrombin time and international normalized ratio values when compared with the reoperation group $(P<.0005)$. No significant differences were observed with regard to other coagulation parameters or chest tube output (see Table E1). There was a significant decrease in median blood product use after intervention with rFVIIa (Table 3). However, blood product use after intervention did not differ between the 2 groups (Figure 1, $C$ and $D$ ).

In the rFVIIa group hemostasis was achieved in $9(75 \%)$ of 12 patients. Chest tube output decreased from 5.0 to 1.4 $\mathrm{mL} \cdot \mathrm{kg}^{-1} \cdot \mathrm{h}^{-1}(P=.002$; Figure $2, A)$. Reoperation for bleeding was required in 3 of 12 patients in this group (patients 2, 3, and 11). One patient (patient 11) bled from a right coronary button after a valve-sparing aortic root and ascending and hemiarch replacement. In the other 2 cases no obvious source of bleeding was identified.

In the reoperation group chest tube output decreased from 3.6 to $1.3 \mathrm{~mL} \cdot \mathrm{kg}^{-1} \cdot \mathrm{h}^{-1}(P=.005$; Figure $2, B)$. Eight 

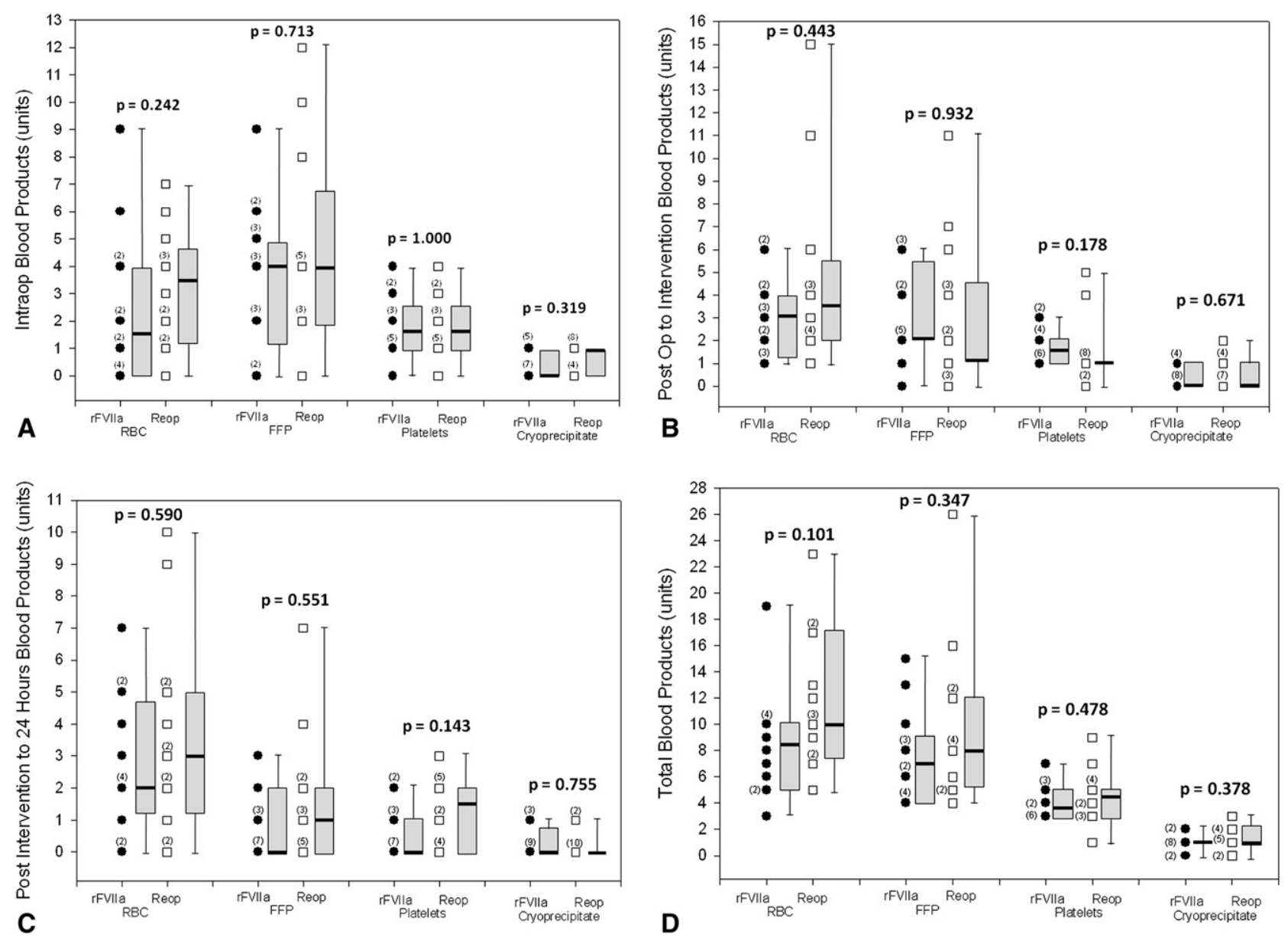

FIGURE 1. (A) Comparison of transfusion requirements intraoperatively, (B) postoperatively but before intervention with recombinant activated factor VII ( $r F$ VIIa) or reoperation, and (C) after intervention to 24 hours after the primary operation and (D) total blood product use in patients receiving rFVIIa or reoperation for refractory coagulopathy in the intensive care unit. Numbers in parentheses represent multiple patients receiving the specified amount of blood product. Box plots show the median, interquartile range, and minimum and maximum values. RBC, Red blood cells; Reop, reoperation; FFP, fresh frozen plasma.

patients were found to have surgically correctable bleeding. One patient bled from a vein graft, requiring reinstitution of cardiopulmonary bypass for repair and a dose of rFVIIa to

TABLE 3. Efficacy of intervention in patients who received rFVIIa or reoperation for refractory coagulopathy in the intensive care unit

\begin{tabular}{lccc}
\hline & $\begin{array}{c}\text { Preintervention, } \\
\text { median (range) }\end{array}$ & $\begin{array}{c}\text { Postintervention, } \\
\text { median (range) }\end{array}$ & $\begin{array}{c}\boldsymbol{P} \\
\text { value }\end{array}$ \\
\hline rFVIIa & & & \\
RBC & $5.0(1-11)$ & $2.0(0-7)$ & .022 \\
FFP & $6.0(4-13)$ & $0.0(0-3)$ & .002 \\
Platelets & $3.0(2-6)$ & $0.0(0-2)$ & .003 \\
Cryoprecipitate & $1.0(0-1)$ & $0.0(0-1)$ & .034 \\
Reoperation & & & \\
RBC & $6.5(2-17)$ & $3.0(0-10)$ & .084 \\
FFP & $7.0(3-19)$ & $1.0(0-7)$ & .002 \\
Platelets & $3.0(1-7)$ & $1.5(0-3)$ & .019 \\
Cryoprecipitate & $1.0(0-3)$ & $0.0(0-1)$ & .018 \\
\hline
\end{tabular}

$r F$ VIIa, Recombinant activated factor FVII; $R B C$, red blood cells; $F F P$, fresh frozen plasma. control bleeding in the OR. In 4 patients no obvious bleeding source was identified. One of these patients required rFVIIa in the OR for hemostasis during reoperation after aortic and mitral valve replacements and tricuspid repair. Overall, 15 patients required reoperation for bleeding, resulting in a calculated reoperation rate of $3.6 \%(15 / 421)$.

Total OR time was significantly lower in the rFVIIa group (444 vs 599 minutes, $P=.001$ ). No significant differences in postoperative ventilator hours, ICU LOS, or LOS calculated from the time of surgical intervention to discharge were demonstrated (see Table E2).

\section{End Points for Safety}

In-hospital survival in both patient groups was $100 \%$. There were no significant differences in infection, thrombosis, or renal failure (see Table E2). In the rFVIIa group there was 1 pulmonary embolism and 1 episode of renal failure. The pulmonary embolus was detected incidentally on a routine predischarge computed tomographic angiogram after 

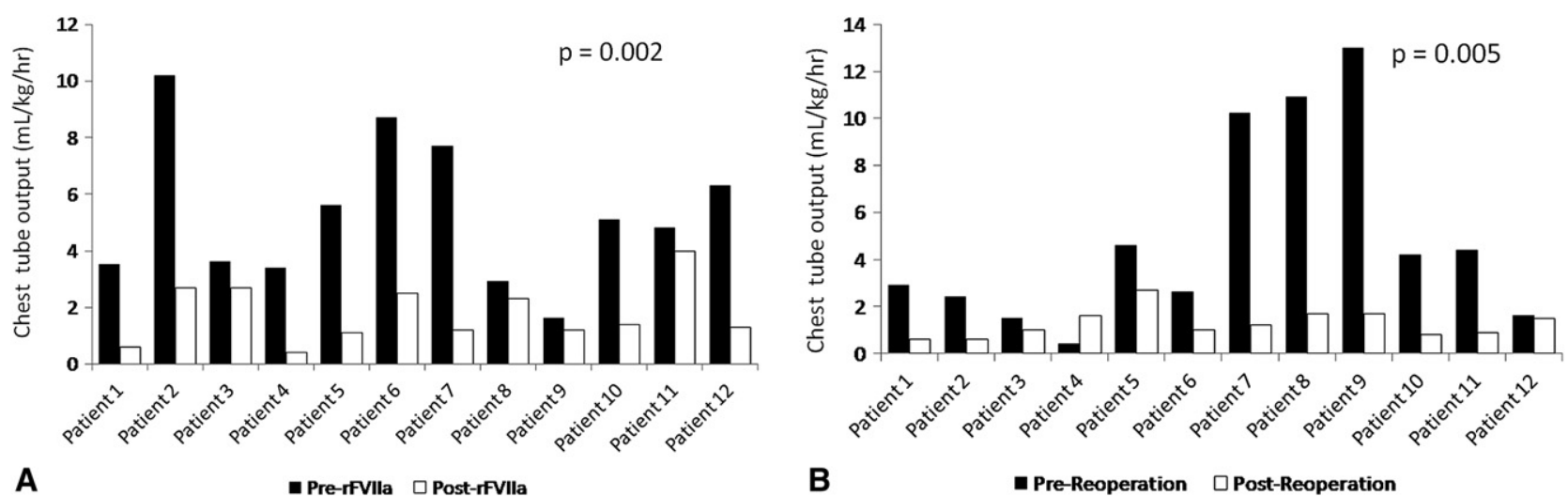

FIGURE 2. Chest tube output (A) before and after recombinant activated factor VII ( $r F$ VIIa) administration and (B) before and after reoperation for refractory coagulopathy in the intensive care unit.

aortic surgery and caused no symptoms. The episode of renal failure occurred in a patient with no preexisting renal disease and resolved completely. Both of these patients required reoperation for continued bleeding after rFVIIa administration.

\section{End Points for Economic Outcomes}

No statistically significant differences were observed with regard to hospital cost, charges, reimbursement, or profit margin (see Table E3).

\section{DISCUSSION}

Excessive bleeding after cardiovascular surgical procedures has been reported to occur in up to $20 \%$ of patients, and surgical re-exploration might be required in $2 \%$ to $5 \%$ of patients. ${ }^{1-3,11,20}$ Complex cardiac procedures present a 3-fold increased risk in rates of reoperation for bleeding. ${ }^{2,3}$ Both surgical re-exploration and excessive blood product replacement increase risk of infection, multiorgan failure, thromboembolism, increased hospital and ICU LOS, and mortality. ${ }^{1-7}$ Refractory blood loss despite maximal standard therapy might be seen in up to $2 \%$ of cases. $^{12,17,20}$ In these cases other options to control refractory hemorrhage are required.

rFVIIa was introduced in the United States in 1999. Its mechanism of action is 3-fold. First, rFVIIa binds to exposed tissue factor (TF) at the site of injury, activating factor $\mathrm{X}$ and leading to thrombin formation and platelet activation. ${ }^{8,20}$ Second, rFVIIa binds to activated platelets causing activation of factor $\mathrm{X}$ leading to TF-independent thrombin generation. ${ }^{8}$ Finally, rFVIIa stabilizes clotting by means of activation of the thrombin activation fibrinolysis inhibitor. ${ }^{8}$

In 2004, we began using rFVIIa in the OR for refractory bleeding after complex cardiovascular procedures. We found that it effectively controlled nonsurgical bleeding, reduced blood product use, and avoided reoperation for delayed sternal closure. ${ }^{15}$ In 2006, we began to use rFVIIa in the ICU for refractory bleeding. Others have found that this has reduced massive transfusion and reoperation. ${ }^{9,10,12,14-16,18,19}$ However, this has not translated into shorter LOS or lower morbidity or mortality. Concerns regarding safety and cost continue to create controversy about the use of rFVIIa in this setting. ${ }^{8,19,20}$

In the present comparison of reoperation with rFVIIa administered in the ICU, we found both groups to be comparable with regard to preoperative, intraoperative, and postoperative characteristics. Both groups demonstrated a similar significant decrease in chest tube output and blood product use. Nine $(75 \%)$ of 12 patients in the rFVIIa group avoided reoperation. Similarly, reoperation was effective in achieving hemostasis in $10(83.3 \%)$ of 12 patients, with 2 requiring rFVIIa during reoperation. Patients receiving rFVIIa had a significant decrease in the median OR time compared with that seen in the reoperation group but no significant differences in economic outcomes.

We found, as have others, that administration of rFVIIa in the ICU produced a significant decrease in chest tube output and blood product use,,${ }^{9,10,12,14-16,18,19}$ with similar results observed with reoperation. Although no differences were detected between the groups, this should be interpreted with caution because patients suspected of having a surgical source of bleeding underwent reoperation.

Similar to other studies, prothrombin time and international normalized ratio were significantly less in patients who received rFVIIa compared with values seen in patients undergoing reoperation..$^{9,12,14-16,18}$ In vitro rFVIIa exerts an effect on the active ingredients in the test tube at laboratory temperature and might not be representative of in vitro effects. ${ }^{8}$ Thromboelastographic analysis might have predictive value on potential response to rFVIIa but has been found to poorly identify and monitor changes in coagulation after intervention. ${ }^{21}$ Adequacy of management of abnormal coagulation parameters, hypothermia, acidosis, and hypocalcemia (predictive of poor response to rFVIIa) might explain the wide range in response to rFVIIa, which is 
reported to be between $60 \%$ and $100 \% .^{8-10,13-15,18,19,22}$ In our study these parameters were similar and within normal ranges in both groups before intervention.

In this high-risk cohort the incidence of postoperative bleeding was $5.9 \%$, and the reoperation rate was $3.6 \%$, which is consistent with published reports. ${ }^{1-3,7,20}$ Nine of 12 patients in the rFVIIa group avoided reoperation. In the 3 re-explored patients, only 1 was found to have surgically correctable bleeding.

In our study rFVIIa was administered at an average single dose of $89.9 \pm 7.1 \mu \mathrm{g} / \mathrm{kg}$. Doses of rFVIIa used to control postoperative hemorrhage in patients undergoing cardiac surgery have ranged between 11 and $192 \mu \mathrm{g} / \mathrm{kg}$ per dose in published reports. ${ }^{9-19}$ Romagnoli and colleagues ${ }^{9}$ conducted a matched case-control analysis evaluating the use of $1.2 \mathrm{mg}$ of rFVIIa (11-21.5 $\mu \mathrm{g} / \mathrm{kg}$ per dose), demonstrating a significant decrease in re-exploration and a trend toward a decrease in mortality in the rFVIIa group. Masud and associates ${ }^{18}$ observed a significant reduction in PRBC use but no dose-response effect after rFVIIa administration among all dosing quartiles greater than $30 \mu \mathrm{g} / \mathrm{kg}$. Consensus recommendations are for 1 to 2 doses of 35 to $70 \mu \mathrm{g} /$ $\mathrm{kg}$ to be given for bleeding that is refractory to standard hemostatic therapies. ${ }^{23}$

Timing of rFVIIa dose relative to its efficacy is also of interest. Prophylactic use of rFVIIa is not advocated because the risks of rFVIIa might outweigh the benefits. ${ }^{20}$ More relevant is the timing of rFVIIa administration as rescue therapy for refractory bleeding. Karkouti and coworkers ${ }^{5}$ demonstrated that a transfusion requirement of 5 units of PRBCs during the perioperative period increases the odds for in-hospital mortality by 8 -fold. They also evaluated early ( $\leq 8$ units of PRBCs) versus late ( $>8$ units of PRBCs) administration of rFVIIa and found a mortality rate of $7.6 \%$ in the early treatment group compared with $27.1 \%$ in the late group, ${ }^{11}$ a finding seen in other series. ${ }^{13}$ This supports the early use of rFVIIa provided there are adequate amounts of circulating factors. ${ }^{11,14,17}$ Our study reflects this approach because a median of 5.0 (range, 1-11) units of PRBCs was administered before rFVIIa.

Thromboembolic complications are of particular concern with rFVIIa use. ${ }^{19}$ The TF-rFVIIa interaction occurs at many levels, including the subendothelium, atherosclerotic plaques, and ischemic myocardium. ${ }^{8,12,24} \mathrm{TF}$ circulates freely in patients with acute coronary syndromes and is disseminated with the systemic inflammatory response to cardiopulmonary bypass. ${ }^{8,24}$ As such, the interaction between circulating TF and rFVIIa in cardiac surgical patients might result in a hypercoagulable state. ${ }^{8,24} \mathrm{~A}$ review of the US Food and Drug Administration's Adverse Event Reporting System database for rFVIIa between 1999 and 2004 suggested there were increased thromboembolic events in patients treated for unlabeled conditions, with 1 in 50 experiencing a thromboembolic complication and 1 in 200 patients dying. ${ }^{25}$ Thrombosis rates reported in case reports and case-control series in patients undergoing cardiac surgery range from $0 \%$ to $25 \% .{ }^{9,10,12,14-16,18,19}$ The use of rFVIIa has been associated with increased renal failure. ${ }^{12,15} \mathrm{~A}$ comprehensive Canadian review demonstrated a major morbidity rate of $44 \%$ in patients receiving off-label use of rFVIIa in cardiac surgery, but this did not differ from a separate reference cohort of cardiac surgical patients who did not receive $\mathrm{rFVIIa}{ }^{17}$ A recent meta-analysis including 5 studies and a randomized placebo-controlled trial both evaluated rFVIIa use for refractory bleeding in patients undergoing cardiac surgery and showed an increased but not statistically significant incidence of stroke. ${ }^{19,22}$ Our study demonstrated a very low incidence of adverse effects, with no significant differences in the incidence of infection, thrombosis, or renal failure between the 2 groups. Two adverse events (1 pulmonary embolism and 1 episode of renal failure) were observed in the rFVIIa group. However, both patients also required reoperation for continued bleeding after rFVIIa administration. A well-designed randomized controlled trial is needed to adequately determine the risk of rFVIIa administration in this patient population.

With regard to the potential clinical benefits of rFVIIamediated reduction in blood use, Gelsomino and colleagues ${ }^{16}$ demonstrated a significant reduction in both mechanical ventilation time and ICU LOS with use of low-dose rFVIIa. However, Tritapepe and associates ${ }^{14} \mathrm{dem}-$ onstrated no difference in ICU or hospital LOS in 23 patients with refractory bleeding undergoing acute aortic dissection surgery with deep hypothermic circulatory arrest compared with that seen in 23 matched control subjects. No significant effect on survival has been observed in patients receiving rFVIIa for refractory bleeding after cardiac surgery. ${ }^{9,14,16,19,22}$ The only published randomized placebocontrolled trial addressing rFVIIa use in this population did not address any of the above end points; however, a nonstatistically significant doubling of mortality was observed. ${ }^{19}$ It is possible that the lack of statistical significance might have been the result of a type II error involving inadequate enrolment to detect this difference. ${ }^{19}$ Our study demonstrated a significant difference in median OR time in the rFVIIa group that was attributable to the low incidence of reoperation in this group. Median ventilator time, ICU LOS, and hospital LOS were not significantly different, and in-hospital survival for both groups was $100 \%$. This suggests that the efficacy of rFVIIa use in this setting might be equivalent to that of reoperation in select patients. Additional adequately powered studies will be required to evaluate this scenario and further address safety concerns.

Excessive postoperative bleeding after cardiovascular surgical procedures places a high demand on hospital 
resources, leading to increased hospital costs. ${ }^{6,7}$ Strategies that can effectively reduce the incidence or severity of this complication might potentially reduce morbidity, mortality, resource use, and cost. ${ }^{6,7}$ When comparing rFVIIa administration in the ICU with reoperation for refractory bleeding after cardiovascular surgery, we found the groups to be comparable, with no significant differences in hospital cost, charges, reimbursement, or profit. The reduction in OR time and resource use observed in the rFVIIa group did not appear to translate into a significant decrease in hospital costs. A study performed by Christensen and coworkers ${ }^{7}$ comparing patients with and without excessive postoperative hemorrhage after cardiac surgery demonstrated that ICU stay dominated overall cost $(51 \%)$, followed by the cost of manpower requirements $(28 \%)$ and LOS in the general ward $(10 \%)$, with blood transfusion and cost of reoperation accounting for only $4 \%$ and $3 \%$ of the cost, respectively. This might explain the lack of effect that OR time had on cost in our study. However, this might allow the opportunity to use these resources in other areas to generate additional revenue.

Several limitations need to be considered when interpreting our results. Our study is a retrospective nonrandomized trial with a limited sample size and therefore underpowered. Our findings should therefore be viewed as associative rather than causative. Eight of the 12 patients in the reoperation group were found to have a surgically correctable cause of bleeding, suggesting both that clinical judgment is important to the success of rFVIIa treatment and an inherent selection bias in this study. In addition, it is possible that nonsignificant differences between the groups with regard to the distribution of various patients' demographics and risk variables (Table 1) might have affected bleeding outcomes in this analysis. All patients in the reoperation group were identified before July 2006, and all patients meeting bleeding criteria after July 2006 were given rFVIIa. This introduces a time-related bias because no patients in the reoperation group had the option of receiving rFVIIa. We did not follow any long-term outcome data for either group in this study. Hospital cost, charge, and reimbursement data might be fairly unique to our institution and might not be widely applicable. We attempted to adjust cost data for inflation and increase in hospital capital expenditures over the study timeframe; however, a more concurrent treatment and control group is preferred.

In conclusion, rFVIIa administration in the ICU appears to be comparable with reoperation with respect to efficacy in patients with refractory bleeding after complex cardiovascular surgery. Reduction in reoperation and OR time and cost of rFVIIa did not correlate with any difference in overall cost. In properly selected patients rFVIIa can be used as an alternative to reoperation for bleeding after cardiovascular surgery. Future prospective, randomized controlled trials are needed to clearly assess the safety of off-label use of rFVIIa in this setting.

\section{References}

1. Dacey LJ, Munoz JJ, Baribeau YR, Johnson ER, Lahey SJ, Leavitt BJ, et al. Reexploration for hemorrhage following coronary artery bypass grafting. Arch Surg. 1998;133:442-7.

2. Moulton MJ, Creswell LL, Mackey ME, Cox JL, Rosenbloom M. Reexploration for bleeding is a risk factor for adverse outcomes after cardiac operation. J Thorac Cardiovasc Surg. 1996;111:1037-46.

3. Unsworth-White MJ, Herriot A, Valencia O, Poloniecki J, Smith EEJ, Murday AJ, et al. Resternotomy for bleeding after cardiac operation: A marker for increased morbidity and mortality. Ann Thorac Surg. 1995;59:664-7.

4. Koch CG, Li L, Duncan AI, Mihaljevic T, Cosgrove DM, Lamp FD, et al. Morbidity and mortality risk associated with red blood cell and blood-component transfusion in isolated coronary artery bypass grafting. Crit Care Med. 2006;34:1608-16.

5. Karkouti K, Wijeysundera DN, Yau TM, Beattie WS, Abdelnaem E, McCluskey SA, et al. The independent association of massive blood loss with mortality in cardiac surgery. Transfusion. 2004;44:1453-62.

6. Murphy GJ, Reeves BC, Rogers CA, Rizvi SIA, Culliford L, Angelini GD. Increased mortality, postoperative morbidity, and cost after red blood cell transfusion in patients having cardiac surgery. Circulation. 2007;116:2544-52.

7. Christensen MC, Krapf S, Kempel A, von Heymann C. Costs of excessive postoperative hemorrhage in cardiac surgery. J Thorac Cardiovasc Surg. 2009;138: 687-93

8. Al-Ruzzeh S, Ibrahim K, Navia JL. Con: the role of recombinant factor VIIa in the control of bleeding after cardiac surgery. J Cardiothorac Vasc Anesth. 2008; 22:783-5.

9. Romagnoli S, Bevilacqua S, Gelsomino S, Pradella S, Ghilli L, Rostagno C, et al. Small-dose recombinant activated Factor VII (NovoSeven) in cardiac surgery. Anesth Analg. 2006;102:1320-6.

10. Raivio P, Suojaranta-Ylinen R, Kuitunen AH. Recombinant factor VIIa in the treatment of postoperative hemorrhage after cardiac surgery. Ann Thorac Surg. 2005;80:66-71.

11. Karkouti K, Yau TM, Riazi S, Dattilo KM, Wasowicz M, Meineri M, et al. Determinants of complications with recombinant factor VIIa for refractory blood loss in cardiac surgery. Can J Anesth. 2006;53:802-9.

12. Karkouti K, Beattie WS, Wijeysundera DN, Yau TM, McCluskey SA, Ghannam M, et al. Recombinant factor VIIa for intractable blood loss after cardiac surgery: a propensity score-matched case-control analysis. Transfusion. 2005; $45: 26-34$.

13. Clark AD, Gordon WC, Walker ID, Tait RC. "Last-ditch" use of recombinant factor VIIa in patients with massive haemorrhage is ineffective. Vox Sang. 2004;86:120-4.

14. Tritapepe L, De Santis V, Vitale D, Nencini C, Pellegrini F, Landoni G, et al. Recombinant activated factor VII for refractory bleeding after acute aortic dissection: a propensity score analysis. Crit Care Med. 2007;35:1685-90.

15. Bowman LJ, Uber WE, Stroud MR, Christiansen LR, Lazarchick J, Crumbley AJ III, et al. Use of recombinant activate factor VII concentrate to control postoperative hemorrhage in complex cardiovascular surgery. Ann Thorac Surg. 2008;85:1669-77.

16. Gelsomino S, Lorusso R, Romagnoli S, Bevilacqua S, De Cicco G, Bille G, et al Treatment of refractory bleeding after cardiac operations with low-dose recombinant activated factor VII (NovoSeven): a propensity score analysis. Eur J Cardiothorac Surg. 2008;33:64-71.

17. Karkouti K, Beattie WS, Arellano R, Aye T, Bussieres JS, Callum JL, et al Comprehensive Canadian review of the off-label use of recombinant activate factor VII in cardiac surgery. Circulation. 2008;118:331-8.

18. Masud F, Bostan F, Chi E, Pass SE, Samir H, Stuebing K, et al. Recombinant factor VIIa treatment of severe bleeding in cardiac surgery patients: a retrospective analysis of dosing, efficacy, and safety outcomes. J Cardiothorac Vasc Anesth. 2009;23:28-33.

19. Gill R, Herbertson M, Vuylsteke A, Skov Olsen P, von Heymann C, Mythen M, et al. Safety and efficacy of recombinant activated factor VII: a randomized placebo-controlled trial in the setting of bleeding after cardiac surgery. Circulation. 2009;120:21-7.

20. Karkouti K, Beattie WS. Pro: the role of recombinant factor VIIa in cardiac surgery. J Cardiothorac Vasc Anesth. 2008;22:779-82.

21. Wasowicz M, Meineri M, McCluskey SM, Mitsakakis N, Karkouti K. The utility of thromboelastography for guiding recombinant activate factor VII therapy for 
refractory hemorrhage after cardiac surgery. J Cardiothorac Vasc Anesth. 2009; 23:828-34.

22. Zangrillo A, Mizzi A, Biondi-Zoccai G, Bignami E, Grazia Calabro M, Pappalardo F, et al. Recombinant activated factor VII in cardiac surgery: a meta-analysis. J Cardiothorac Vasc Anesth. 2009;23:34-40.

23. Karkouti K, Beattie WS, Crowther MA, Callum JL, Chun R, Fremes SE, et al. The role of recombinant factor VIIa in on-pump cardiac surgery: proceeding of the Canadian consensus conference. Can J Anesth. 2007;54:573-82.

24. Hardy JF, Belisle S, Van der Linden P. Efficacy and safety of activated recombinant factor VII in cardiac surgical patients. Curr Opin Anaesthesiol. 2009;22: 95-9.

25. O'Connell KA, Wood JJ, Wise RP, Lozier JN, Braun MM. Thromboembolic adverse events after the use of recombinant human coagulation factor VIIa. JAMA. 2006;295:293-8.

\section{Discussion}

Dr Arvind K. Agnihorti (Boston, Mass). Thank you, Dr Cohn, and thank you, Dr Toole, for this interesting study about a potentially useful adjunct in cardiac surgery. I have 2 comments and then a few questions.

As I read your article, I thought about bleeding in postoperative cardiac surgery and how we deal with a continuum from coagulopathy to surgical sources of bleeding; the 2 obviously are interrelated, and one can beget the other. In this article, which is retrospective, your surgeons tried to determine whether the patients had a coagulopathy or a surgical source of bleeding and then proceeded to either reoperate on them or potentially to use this drug. Therefore these are really 2 different populations of patients, and I think that limits the way that we can approach a comparison, as it was done in your study.

The second thing I wanted to point out was that the use of this drug did not appear to improve the outcomes for your patients. Therefore another way to look at this study is that reoperation in the absence of factor VII is also a safe and efficacious way to deal with postoperative hemorrhage, and I was a bit surprised that the use of this drug did not show any apparent reduction in cost.

I have a couple of questions. The first has to do with safety. In the group of patients who received factor VII, $25 \%(n=3)$ ultimately required an operation. In that group 2 of 3 had a complication that might be attributed to stroke: 1 had a pulmonary embolism, and 1 had renal failure. I want you to comment on the possible risk of application of this drug in a patient who has surgical bleeding and is being treated for coagulopathy.

Dr Toole. Thank you very much for those comments. I think that is a very important point and one that we have gone to great lengths to minimize: the administration of a thrombogenic drug to a patient with a relatively normal coagulation system. As you have pointed out, there seems to be a continuum from surgical bleeding to coagulopathy. The definition of surgical bleeding at our institution might be changing, as referenced by the change in our practices from reoperation to administering factor VII to almost everybody. I think that the reason we only found 1 patient with surgical bleeding in the factor VII group is that a lot of things that we would consider surgical bleeding might have stopped with factor VII. Examples would be sternal wires and small mediastinal vessels.

Your concerns about safety are appropriate. Certainly we did not have the statistical power to make any comments about that. I think it is a point worth making that designing a study to detect differences in safety is extremely difficult. Gill, in the Journal of Thoracic and Cardiovascular Surgery in 2009, consented more than 2600 patients and only dosed about 170. The amount of work to consent patients and then randomize them into a study is enormous. In our study only $5 \%$ of high-risk patients had significant postoperative bleeding. This is an inherent problem with prospectively studying these patients. Even with their cohort of 170 patients, they believed that they were underpowered to make any comment on statistical significance as far as safety.

Dr Agnihotri. Did you look at postoperative creatinine values in your patients? I noted that the renal failure rate was not statistically different, but did you see any increase in the treatment group in terms of their peak creatinine values?

Dr Toole. We did not see that.

Dr Agnihotri. You chose a dose of about $90 \mu \mathrm{g} / \mathrm{kg}$ as a single dose. Others have used smaller doses and given multiple smaller doses. Do you have experience with that, and can you comment on why you chose that dose?

Dr Toole. We began using the $90 \mu \mathrm{g} / \mathrm{kg}$ dose because that is the recommended dose set forth by the manufacturer for the treatment of patients with hemophilia. More recent studies suggest that earlier dosing and smaller doses, with ranges between 30 and $70 \mu \mathrm{g} /$ $\mathrm{kg}$, might be effective. To some extent, we have adopted that strategy.

Dr Agnihotri. Thank you very much.

Dr Simon Moten (Melbourne, Australia). At our institution, we have a large experience with the use of recombinant factor VII and are currently involved in a randomized controlled trial for its use in the operative setting. My comment and question is that in the postoperative setting, if people are bleeding, the important factor is the timing at the time of intervention when you realize that patients do require further intervention to correct their bleeding, either return to the operating theater or other measures. In your study did you find that there was any difference in the timing between the 2 groups that might have led to a difference in their outcomes? Certainly I believe that earlier intervention in this group is important for reducing the overall complication rate.

Dr Toole. I agree with you wholeheartedly. We did not specifically look at timing. The bleeding criteria that we used measured chest tube output for the 2 hours before intervention. Once a patient reached the criteria for either reoperation or dosing with factor VII, no more than 2 hours had passed. However, we did have several patients, especially in the earlier reoperation group, who had moderate chest tube output not meeting the bleeding criteria overnight but that increased, and these patients underwent reoperation on the following day.

Dr Domenico Paparella (Bari, Italy). It is hard to define coagulopathy. As you know, there are several reasons why we can have coagulopathy after cardiac surgery. It can be platelet dysfunction, hyperfibrinolysis, or coagulation factor consumption. Did you try to analyze the reason for coagulopathy by using any point-of-care test?

Dr Toole. No, we did not.

Dr Paparella. Okay. I think that makes the choice of administering recombinant factor VII to all bleeding patients not very balanced because you do not know why your patients are bleeding.

Dr Toole. Our criteria for giving factor VII required that coagulation test results be relatively normal, by which I mean a platelet 
count of greater than 100,000 , an international normalized ratio of less than 1.5, a complete reversal of the partial thromboplastin time, and a fibrinogen level of greater than 200 , but we did not necessarily use a point-of-care test to adjust those. I think what you are referring to is a thromboelastogram, which we did not routinely use on all bleeding patients postoperatively.

Dr G. Hossein Almassi (Milwaukee, Wis). Did you have in your group of factor VII recipients any patients with diseases that would predispose to bleeding, such as myelomonocytic leukemia, in which no matter what you do they bleed, or any other type of malignancy that would predispose them to it? Do you have any experience in that regard?

Dr Toole. We did not have any patients with any of those conditions or any personal or family history of bleeding disorders.

Dr A. W. Atkinson (Raleigh, NC). The earlier comment that you do not have any quantitative defect in your clinical assessment of why the patient is bleeding and yet he or she is bleeding was interesting, and it appears that when you give some patients factor VII, they stop bleeding. It just might be that we are not doing the right test yet. Maybe we ought to get a quantitative level for factor VII or some other proton, partial thromboplastin time, something we are not doing right so we know when to give this drug. It appears that there is a relative deficiency of this part of the cascade, and we just have not learned to test for it yet. How about that?

Dr Toole. I agree with you. It is difficult to assess exactly what the deficiency is unless there is a specific abnormality that shows up in the coagulation laboratory studies. We try very hard to correct all of those: first so we do not have to give the patient factor VII if they do not need it, but second because once the factor VII is given, it relies on all of those downstream components of the clotting cascade to get the job done. Giving a patient with coagulation abnormalities factor VII is not likely to help them.

Dr Atkinson. There was not anybody who was still bleeding after you fixed the surgical problem if it existed and you gave them factor VII, right?

Dr Toole. That is correct.

Dr Lawrence H. Cohn (Boston, Mass). I have one question. You said it was a very expensive drug. Can you give us a sense of the sort of average cost of the use of this recombinant factor in these patients?

Dr Toole. Factor VII itself costs about $\$ 1000$ a milligram. We gave it in a $90 \mu \mathrm{g} / \mathrm{kg}$ dose. Not everybody uses that dose. Unfortunately, our average patient in South Carolina weighs between 90 and $100 \mathrm{~kg}$, and therefore our average cost of factor VII is about $\$ 9,000$ per dose. 
TABLE E1. Comparison of coagulation parameters in patients before and after administration of rFVIIa or reoperation for refractory coagulopathy in the intensive care unit

\begin{tabular}{|c|c|c|c|}
\hline & rFVIIa $(\mathbf{n}=12)$ & Reoperation $(\mathrm{n}=12)$ & $P$ value \\
\hline \multicolumn{4}{|l|}{ Preintervention, median (range) } \\
\hline aPTT (s) & $40.6(33.0-56.5)$ & $40.8(36.8-67.6)$ & .551 \\
\hline PT (s) & $17.5(10.3-21.9)$ & $17.5(17.1-27.5)$ & .198 \\
\hline INR & $1.37(0.68-1.82)$ & $1.38(1.31-2.49)$ & .219 \\
\hline Fibrinogen (mg/dL) & $281(163-381)$ & $282(122-351)$ & .606 \\
\hline Platelets $\left(1000 / \mathrm{mm}^{3}\right)$ & $134(69-182)$ & $111(48-213)$ & .266 \\
\hline Body temperature $\left({ }^{\circ} \mathrm{C}\right)$ & $35.7(34.9-37.6)$ & $35.6(34.1-36.7)$ & .799 \\
\hline $\mathrm{pH}$ & $7.40(7.29-7.46)$ & $7.41(7.23-7.47)$ & 1.000 \\
\hline Ionized calcium (mmol/L) & $1.11(0.67-1.50)$ & $1.15(0.80-1.35)$ & .932 \\
\hline Chest tube output $\left(\mathrm{mL} \cdot \mathrm{kg}^{-1} \cdot \mathrm{h}^{-1}\right)$ & $5.0(1.6-10.2)$ & $3.6(0.4-13.0)$ & .319 \\
\hline \multicolumn{4}{|l|}{ Postintervention, median (range) } \\
\hline aPTT (s) & $31.8(30.5-39.2)$ & $34.8(30.0-39.1)$ & .175 \\
\hline PT (s) & $11.7(10.8-13.9)$ & $16.4(12.9-20.3)$ & $<.0005$ \\
\hline INR & $0.82(0.73-1.01)$ & $1.25(0.90-1.70)$ & $<.0005$ \\
\hline Fibrinogen (mg/dL) & $296(199-398)$ & $290(199-370)$ & .902 \\
\hline Platelets $\left(1000 / \mathrm{mm}^{3}\right)$ & $112(97-197)$ & $129(90-190)$ & .319 \\
\hline Body temperature $\left({ }^{\circ} \mathrm{C}\right)$ & $37.3(36.0-37.9)$ & $37.4(36.7-38.6)$ & .410 \\
\hline $\mathrm{pH}$ & $7.42(7.30-7.54)$ & $7.40(7.36-7.47)$ & .932 \\
\hline Ionized calcium (mmol/L) & $1.20(1.0-1.4)$ & $1.20(0.9-1.5)$ & .512 \\
\hline Chest tube output $\left(\mathrm{mL} \cdot \mathrm{kg}^{-1} \cdot \mathrm{h}^{-1}\right)$ & $1.4(0.36-4.00)$ & $1.3(0.6-2.7)$ & .266 \\
\hline
\end{tabular}

TABLE E2. Associated outcomes in patients who received rFVIIa or reoperation for refractory coagulopathy in the intensive care unit

\begin{tabular}{lccc}
\hline \multicolumn{1}{c}{ Outcome } & $\begin{array}{c}\text { rFVIIa } \\
(\mathbf{n = 1 2})\end{array}$ & $\begin{array}{c}\text { Reoperation } \\
(\mathbf{n = 1 2})\end{array}$ & $\begin{array}{c}\boldsymbol{P} \\
\text { value }\end{array}$ \\
\hline Survival to discharge & $12(100 \%)$ & $12(100 \%)$ & \\
Permanent stroke & 0 & 0 & \\
Mediastinitis & 0 & 0 & \\
Acute limb ischemia & 0 & 0 & \\
Perioperative MI & 0 & 0 & \\
Pneumonia & 0 & 0 & 1.000 \\
Pulmonary embolism & $1(8 \%)$ & 0 & 1.000 \\
Renal failure & $1(8 \%)$ & 0 & .001 \\
Dialysis required & 0 & 0 & \\
Total OR time (min) & & & \\
$\quad$ Median & 444 & 599 & \\
$\quad$ Range & $359-698$ & $495-754$ & \\
Postoperative ventilator time (h) & & & \\
$\quad$ Median & 17 & 24 & .643 \\
$\quad$ Range & $10-117$ & $12-206$ & \\
Intensive care unit stay (h) & & & \\
$\quad$ Median & 89 & 117 & \\
$\quad$ Range & $41-268$ & $24-301$ & \\
LOS surgery to discharge (d) & & & \\
$\quad$ Median & 9.0 & 8.5 & \\
Range & $4-18$ & $4-23$ & \\
\hline
\end{tabular}

$r F V I I a$, Recombinant activated factor VII; $M I$, myocardial infarction; $O R$, operating room; $L O S$, length of stay. 
TABLE E3. Comparison of economic data in patients who received rFVIIa or underwent reoperation for refractory coagulopathy in the intensive care unit

\begin{tabular}{|c|c|c|c|}
\hline Normalized values & rFVIIa $(n=12)$ & Reoperation $(n=12)$ & $P$ value \\
\hline \multicolumn{4}{|l|}{ Hospital cost adjusted for inflation } \\
\hline Median & $\$ 58,976$ & $\$ 62,433$ & .755 \\
\hline Range & $\$ 40,689$ to $\$ 173,381$ & $\$ 35,253$ to $\$ 139,703$ & \\
\hline \multicolumn{4}{|c|}{ Hospital cost adjusted for capital expenditure } \\
\hline Median & $\$ 60,418$ & $\$ 78,041$ & .220 \\
\hline Range & $\$ 43,944$ to $\$ 187,252$ & $\$ 44,066$ to $\$ 164,849$ & \\
\hline \multicolumn{4}{|l|}{ Hospital charges } \\
\hline Median & $\$ 137,462$ & $\$ 134,156$ & .410 \\
\hline Range & $\$ 98,816$ to $\$ 256,503$ & $\$ 75,931$ to $\$ 235,922$ & \\
\hline \multicolumn{4}{|l|}{ Reimbursement } \\
\hline Median & $\$ 51,132$ & $\$ 54,876$ & .514 \\
\hline Range & $\$ 0$ to $\$ 164,675$ & $\$ 28,489$ to $\$ 177,392$ & \\
\hline \multicolumn{4}{|l|}{ Profit margin adjusted for inflation } \\
\hline Median & $-\$ 16,631$ & $-\$ 3,885$ & .128 \\
\hline Range & $-\$ 57,893$ to $\$ 22,279$ & $-\$ 43,380$ to $\$ 74,801$ & \\
\hline \multicolumn{4}{|c|}{ Profit margin adjusted for capital expenditure } \\
\hline Median & $-\$ 21,419$ & $-\$ 16,885$ & .684 \\
\hline Range & $-\$ 57,893$ to $\$ 11,598$ & $-\$ 69,188$ to $\$ 56,335$ & \\
\hline
\end{tabular}

